\title{
DIFICULDADES DE LEITURA, ESCRITA E NUMERAMENTO NA EDUCAÇÃO SUPERIOR: DISCUSSÕES ACERCA DA REPRODUÇÃO DAS DESIGUALDADES SOCIAIS
}

\author{
DIFICULTADES DE LECTURA, ESCRITURA Y NUMERACIÓN EN LA ENSEÑANZA \\ SUPERIOR: DISCUSIONES SOBRE LA REPRODUCCIÓN DE DESIGUALDADES \\ SOCIALES
}

\begin{abstract}
DIFFICULTIES IN READING, WRITING AND NUMBERING IN HIGHER EDUCATION: DISCUSSIONS ABOUT THE REPRODUCTION OF SOCIAL INEQUALITIES
\end{abstract}

\author{
Lais DONIDA ${ }^{1}$ \\ Soeli Francisca Mazzini Monte BLANCO ${ }^{2}$
}

RESUMO: Este artigo objetiva compreender como as desigualdades sociais originam dificuldades de leitura, escrita, aritmética e como essas questões de ordem social são transformadas em supostos diagnósticos clínico-biológicos em estudantes da Educação Superior. Os contornos metodológicos envolvem um estudo de caso de uma estudante encaminhada para a clínica fonoaudiológica para avaliação clínica. Os dados demonstram que as dificuldades acadêmicas da universitária são consideradas como "alterações de cunho patológico" por que refletem mecanismos de manutenção e reprodução de desigualdades sociais. A Universidade, por sua vez, não consegue fazer com que o apoio pedagógico institucional dê conta das dificuldades da acadêmica, devido às especificidades do curso de graduação. A partir disso, conclui-se que um possível caminho a ser construído no contexto da Educação Superior seja (trans)formar os cursos a partir da perspectiva do Desenho Universal para a Aprendizagem (DUA).

PALAVRAS-CHAVE: Matemática. Escrita. Leitura. Letramento. Universidade.

RESUMEN: Este articulo tiene como objetivo comprender cómo las desigualdades sociales causan dificultades en la lectura, la escritura, la aritmética y cómo estos problemas sociales se transforman en supuestos diagnósticos clínico-biológicos en estudiantes de Enseñanza Superior. Los esquemas metodológicos implican un estudio de caso de un estudiante referido a la clínica de logopedia para evaluación clínica. Los datos demuestran que las dificultades académicas se consideran "alteraciones de naturaleza patológica" porque reflejan mecanismos de mantenimiento y reproducción de las desigualdades sociales. La Universidad, por su parte, no puede hacer que el apoyo pedagógico institucional tenga en cuenta las dificultades académicas, debido a las especificidades del curso de pregrado. A partir de esto, se concluye que un posible camino a construir en el contexto de la Enseñanza Superior es (trans)formar los cursos desde la perspectiva del Diseño Universal para el Aprendizaje (DUA).

\footnotetext{
${ }^{1}$ Universidade Federal de Santa Catarina (UFSC), Florianópolis - SC - Brasil. Doutoranda no Programa de Pósgraduação em Linguística. ORCID: https://orcid.org/0000-0003-3508-7030.E-mail: lais.donida@gmail.com ${ }^{2}$ Universidade do Estado de Santa Catarina (UDESC), Florianópolis - SC - Brasil. Docente do Centro de Educação à Distância (CEAD). Doutorado em Engenharia Química (UFSC). ORCID: https://orcid.org/00000003-1427-1445. E-mail: soeli.francisca@udesc.br
} 
PALABRAS CLAVE: Matemáticas. Escritura. Lectura. Literacidad. Universidad.

ABSTRACT: This article aims to understand how social inequalities cause difficulties in reading, writing, arithmetic and how these social issues are transformed into supposed clinical-biological diagnoses in higher education students. The methodological outlines involve a case study of a student referred to the speech therapy clinic for clinical evaluation. The data demonstrate that the academic difficulties of university student's are considered "alterations of a pathological nature" because they reflect mechanisms of maintenance and reproduction of social inequalities. The University, for its part, is unable to make the institutional pedagogical support account for the academic difficulties, due to the specificities of the undergraduate course. From this, it is concluded that a possible path to be built in the context of Higher Education is to (trans) form the courses from the perspective of Universal Design for Learning (DUA).

KEYWORDS: Mathematics. Writing. Reading. Literacy. University.

\section{Introdução}

As exigências no domínio de práticas de letramentos nas sociedades grafocêntricas também em constante modificação, uma vez que acompanham esse desenvolvimento econômico-político e social (NORONHA, 2019). Com os avanços científico-tecnológicos que estão ocorrendo em nossa sociedade, o domínio da leitura, da escrita e da aritmética se tornam fatores que influenciam os indicadores considerados como determinantes no desenvolvimento ou não de uma nação (UNESCO, 2016).

Dessa forma, há preocupação em quantificar os domínios funcionais de práticas de leitura, escrita e numeramento por parte de organizações e instituições nacionais e internacionais, as quais promovem discussões acerca da alfabetização e suas expressões sociais (CAVACO, 2008; RODRIGUES, 2014). Os censos do Instituto Brasileiro de Geografia e Estatística (IBGE), através da Pesquisa Nacional a Domicílio (PNAD), indicam que o Brasil vem reduzindo os índices de analfabetismo da população com 15 anos ou mais. Ao longo dos últimos anos, houve redução significativa, demonstrando que passou de 12,4\%, em 2001, para 8,7\%, em 2012 (IBGE, 2012). Mas os dados ainda não são satisfatórios, pois revelam que ainda há 13,2 milhões de analfabetos no país (BRASIL, 2014). E, apesar dos avanços, as diferenças educacionais ainda são significativas se comparadas entre as regiões do país, refletindo as diferenças socioeconômicas (IBGE, 2012).

Atualmente, os dois principais indicadores nacionais em que observam dados relacionados à universitários são: o Indicador de Analfabetismo Funcional (INAF), visa analisar os domínios funcionais da população brasileira em termos de leitura, escrita e 
numeramento; e o Indicador de Letramento Científico (ILC), que objetiva "determinar diferentes níveis de domínio das habilidades de letramento no uso da linguagem e dos conceitos do campo da ciência no cotidiano dos brasileiros" (IBLC, 2018, p. 5).

Segundo o INAF (2018), o índice de pessoas entre 15 a 64 anos funcionalmente alfabetizadas é elevado (71\%), contudo, apenas $12 \%$ da população é considerada plenamente alfabetizada. Além disso, na Universidade, embora 96\% dos acadêmicos sejam considerados alfabetizados funcionalmente, somente 34\% dos estudantes alcançaram o nível proficiente, ou seja, dominam as práticas de leitura, escrita e numeramento exigidas pelo nível de escolaridade. Segundo o ILC (2018), apenas 5\% da população brasileira possui letramento científico proficiente. E, com relação à Educação Superior, somente $23 \%$ dos acadêmicos alcança o nível de proficiência.

A partir desse contexto, políticas públicas de acesso (BRASIL, 2007; 2010; 2012), bem como as Políticas Públicas de Inclusão na Perspectiva da Educação Inclusiva (BRASIL, 2008), procurou-se democratizar o acesso à formação de nível superior a um segmento populacional extensivo que antes não tinha oportunidade de ingressar e permanecer nesse segmento educacional. Assim, embora a última década tenha sido marcada pela ampliação e expansão de cursos e instituições de Educação Superior e por mudanças nas formas de ingresso, se antes apenas uma minoria conseguia adentrar nesse nível de ensino, agora há um contingente de estudantes, com trajetórias educacionais e condições socioeconômicas distintas, o que modificou o perfil das Universidades.

Por conseguinte, observam-se dificuldades que até pouco tempo quase não eram notadas: dificuldades em aritmética, falta de conhecimento prévio sobre os conteúdos, poucas práticas de leitura, escrita e numeramento, dificuldades com gêneros acadêmicos (resumos, relatórios, Trabalhos de Conclusão de Curso etc.) , questões econômicas e culturais que influenciam na permanência nas instituições. Ademais, as instituições de ensino evidenciam ações a partir da preocupação em atender as pessoas público-alvo da Educação Especial e aquelas com diagnósticos antes negligenciados, tais como os Transtornos Específicos de Aprendizagem.

$\mathrm{Na}$ literatura da área médica, evidenciada pelo Manual Diagnóstico e Estatístico de Transtornos Mentais (DSM-V) (APA, 2014), os “Transtornos de Aprendizagem" são uma categoria de diagnóstico clínico que descrevem os processos diagnósticos e de intervenção em três principais alterações linguístico-cognitivas: a dificuldade com ênfase na escrita (disgrafia, disortografia), a dificuldade com ênfase na leitura (dislexia), e a dificuldade com ênfase na aritmética (a discalculia). Para que esses diagnósticos sejam afirmados pelos profissionais 
competentes, há a necessidade de descartar uma série de fatores: má alfabetização; problemas familiares, emocionais e de saúde; alterações cognitivo-linguísticas (como outras deficiências); além de realizar intervenção terapêutica intensiva sem haver qualquer evolução na aprendizagem.

Essas alterações, por sua vez, são compreendidas como um "público oculto" nas instituições educacionais, e são definidas dentro de outra grande categoria, os chamados Transtornos Funcionais Específicos (doravante TFE). Estes não são compreendidos como público-alvo da Educação Especial, mas possuem especificidades que não são contempladas dentro de ações institucionais para promoção de práticas de Letramentos. Os TFE, portanto, compreendem pessoas com dislexia, disortografia, disgrafia, discalculia, transtorno de processamento auditivo (central) - TPAC, transtorno de déficit de atenção e hiperatividade TDAH, transtorno desafiador-opositor - TOD (DONIDA, 2018).

Apesar das especificações descritas na literatura, se vê que muitos diagnósticos acabam sendo banalizados devido a não compreensão acerca de aspectos sociais que influenciam nas práticas de Letramentos e também na aprendizagem escolar formal dos indivíduos em nossa sociedade. $\mathrm{O}$ que se observa são diagnósticos que se constroem socialmente a partir de discursos (de professores, de colegas, de familiares) dentro das instituições de ensino e que se voltam à justificar dificuldades que seriam "individuais", bem como justificam o "fracasso" do estudante perante o "não-aprender" (ELIASSEN, 2018). Assim, problemas oriundos de desigualdades sociais, de diferenças individuais, de normatização da heterogeneidade humana, são definidos, classificados, rotulados, medicados e "remediados" no contexto das definições das illnesses (enfermidades, doenças).

Essa temática traz à tona importante discussão acerca de termos como sucesso e fracasso acadêmico, em que estudantes com dificuldades de leitura, escrita e numeramento que ingressam na Educação Superior e acabam sofrendo um processo de "exclusão", pois ainda se encontram poucas ações no meio acadêmico que apoiem estes estudantes (DONIDA; SANTANA, 2019). Observa-se também que aspectos teórico-epistemológicos têm sido pouco discutidos, tais como o impacto das práticas de letramentos na construção das dificuldades acadêmicas.

As práticas de leitura, escrita e oralidade são discutidas por Street (2014), que as define como práticas sociais de letramentos. Para o autor, as práticas sociais de utilização da leitura, da escrita e da oralidade são múltiplos e dependem do contexto histórico e cultural, bem como da observação de como as pessoas os utilizam em determinado contexto. Ou seja, não há uma prática social que se sobreponha às demais. Segundo Donida et.al. (2019), as 
práticas de letramentos envolveriam também práticas de sinalização, ou seja, há o reconhecimento das práticas sociais em línguas de sinais em paralelo com as práticas de oralidade em nossa sociedade. Essas práticas sociais, portanto, são práticas funcionais para os sujeitos, o que se afasta do conceito de funcionalidade utilizada pelos indicadores nacionais de alfabetização funcional, por exemplo.

Nesse sentido, as práticas de numeramentos também são compreendidas como aquelas que são contextualizadas a partir de um momento histórico, definido dentro de determinada cultura, como uma manifestação desta, trazendo à tona todos os artefatos histórico-culturais de determinada comunidade. Os numeramentos são os usos e expressões sociais dessas práticas que se utilizam de outros signos para expressar os atos em sociedade (SILVA, 2012; D’AMBRÓSIO, 2018). A partir do exposto, o reconhecimento das práticas sociais de leitura, escrita, oralidade/sinalização e numeramento são importantes fontes de pesquisa para se observar as dificuldades apresentadas por escolares ou acadêmicos e que revelam estratégias de ensino e aprendizagem insuficientes para alcançar as exigências esperadas pelas instituições educacionais.

A partir do exposto, o presente estudo objetiva responder a alguns questionamentos, como: As dificuldades educacionais são percalços que acompanham os participantes desde a escola ou surgiram após o ingresso na Universidade? Quais eram as práticas de letramentos e numeramentos antes do ingresso na instituição de Educação Superior? E após? Como a família se organizava quanto às práticas sociais de leitura, escrita, aritmética e oralidade? A partir do exposto, o objetivo desta pesquisa é compreender como as desigualdades sociais originam dificuldades de leitura, escrita, aritmética e oralidade e como essas questões de ordem social são transformadas em supostos diagnósticos clínico-biológicos em estudantes da Educação Superior.

\section{Contornos metodológicos}

Esta pesquisa é um estudo de caso envolvendo uma estudante universitária que buscou a Clínica Escola de Fonoaudiologia da Universidade Federal de Santa Catarina a partir do encaminhamento de outros profissionais da saúde para realização de avaliação fonoaudiológica devido a dificuldades acadêmicas. Suas queixas para o encaminhamento referiam-se a um suposto diagnóstico de discalculia, em que ela reverbera em seus enunciados: 
Em anatomia eu quase reprovei por que a gente tem anatomia dental, que é por número. Na hora da prova você pega o dente e diz que número que é. E várias vezes eu escrevi ao contrário: se era 16 eu escrevi 61. Eu fazia essa inversão, mas na hora que eu escrevia eu via certo. Não sei até que ponto isso é nervosismo ou é um problema. E eu percebo que eu tinha muitos problemas assim com números, de inverter, fazer isso com frequência, quando eu trabalhei em consultório odontológico e a gente tinha que organizar as pastas pelos números dos prontuários [...]. Por exemplo, a parte de [anatomia]de coração, eu troco muito direita e esquerda [...].

A partir disso, foi realizada uma investigação minuciosa com a estudante, através dos seguintes instrumentos: i) Entrevista semi-direcionada; ii) Utilização do Questionário de Hábitos de Leitura e Escrita (desenvolvido pelo Grupo de Estudos em Linguagem, Cognição e Educação - GELCE, UFSC) ${ }^{3}$; iii) Avaliação clínica fonoaudiológica a partir de uma perspectiva da Neurolinguística Enunciativo-Discursiva (SENHORINI et al., 2016; SANTANA; PIMENTEL, 2017).

Foram realizadas: uma sessão para preenchimento conjunto do questionário, com duração de uma hora; uma sessão para entrevista, com duração de uma hora; duas sessões para avaliação fonoaudiológica, com duração de uma hora cada. As sessões foram gravadas em áudio e transcritas posteriormente. A avaliação fonoaudiológica foi realizada na sala do GELCE, localizada no Centro de Ciências da Saúde (CCS/UFSC).

Para fins de preservação da identidade da participante, será utilizado o nome fictício de Alice. A participante assinou o Termo de Consentimento Livre e Esclarecido inscrito no Comitê de Ética e Pesquisa da Universidade Federal de Santa Catarina (CEP-UFSC) sob o n ${ }^{\circ}$ 55663716.7 .0000 .0121 .

Os dados foram analisados a partir da Sociologia da Educação de Pierre Bourdieu. Para tanto, esse é um movimento que propôs uma teoria praxiológica, um caminho alternativo, que objetiva analisar como as estruturas sociais externas são internalizadas pelos sujeitos e por eles representadas e reproduzidas na prática (NOGUEIRA; NOGUEIRA, 2014).

Os conceitos de capital que perpassam as obras de Pierre Bourdieu refletem como a estruturação do capital é diferenciada e tem relação com alguns componentes sociais específicos. Para tanto, ele define quatro tipos: capital cultural, o capital social, o capital econômico e o capital simbólico.

De acordo com Bourdieu (2012), a família é uma instituição que transmite aos descendentes um certo capital cultural, ou seja, todos os bens simbólicos culturais e sociais que são transmitidos são vistos como um capital, que pode ser rentável (ou seja, valorado

3 Este questionário ainda não se encontra publicado e ainda está sendo adequado a partir de pesquisas desenvolvidas pelo grupo de pesquisa do GELCE.

RIAEE - Revista Ibero-Americana de Estudos em Educação, Araraquara, v. 16, n. 1, p. 341-360, jan./mar. 2021. e-ISSN: 1982-5587 
socialmente, como ler determinado livro, apreciar determinada obra de arte) ou desprestigiado (fazer uso de uma determinada prática de leitura, escrita ou numeramento que não são vistas por pessoas de classificações socioeconômicas mais elevadas como valorativas) ${ }^{4}$. Um dado importante sobre um componente específico do capital cultural é a informação que é repassada sobre a estrutura e o funcionamento dos sistemas de ensino (BOURDIEU, 2012) ${ }^{5}$.

O capital social é descrito como um conjunto de recursos (linguísticos, econômicos, materiais) que fazem com que pessoas se identifiquem como pertencentes a certo grupo social, compartilhe certas crenças, atitudes, gostos. O capital econômico diz respeito ao rendimento financeiro, à rentabilidade do trabalho, das ações no mercado etc. E o capital simbólico, por fim, é traduzido no prestígio social que os sujeitos possuem frente a um determinado campo e pode fazer uso ou não dos capitais sociais, econômicos e/ou culturais (BOURDIEU, 2012).

Dessa forma, se mobiliza aqui uma concepção teórico-metodológica que compreende o sistema educacional como desigual, como reprodutor de estruturas/classificações sociais e que entende que as formas de socialização dos sujeitos obedecem a certas regras a depender do grupo social a que se pertence. Dessa forma, as valorações dadas à educação, o quanto se investe nela e de que forma isso ocorre sofrerá variações a depender de questões relacionadas ao capital, seja ele econômico, cultural, social ou simbólico (BOURDIEU, 2012; 2011[1984]; BOURDIEU; PASSERON, 2014[1964]).

\section{Resultados e discussões}

Inicialmente é relevante pontuar que os dados serão aqui apresentados de maneira sucinta, visto a necessidade de adequação para a publicação. Portanto, alguns recortes foram realizados e optou-se por revelar e descrever um panorama geral do caso ao leitor. Quanto à avaliação fonoaudiológica, esta descartou alterações linguístico-cognitivas, contudo, forneceu

${ }^{4}$ Esse tipo de capital, por sua vez, se manifesta sob outras três formas: o estado incorporado, o estado objetivado e o estado institucionalizado. $\mathrm{O}$ primeiro, o estado incorporado, diz respeito à cultura à qual o sujeito tem sua socialização logo nos seus primeiros momentos de vida, incorporando-se e orientando suas ações sobre o mundo, sua língua, seus conhecimentos, suas ideologias, seus gostos. O estado objetivado passa a identificar as posses materiais, objetificadas, passando a ter um caráter de pertencimento ao sujeito, tais como livros, filmes, quadros, etc. O capital ou estado institucionalizado, por sua vez, refere-se à aquisição de certificados ou diplomas educacionais, conferindo aos detentores e a seus aspirantes, certa valorização ou prestígio social (BOURDIEU, 2012).

${ }^{5}$ Bourdieu (2012) torna-se um dos principais estudiosos que se propunham a observar como a cultura torna-se um mecanismo de violência simbólica, como há a manutenção das desigualdades sociais, principalmente frente às instituições de ensino, como as lutas entre as classificações sociais ocorrem, de que forma e porque acontecem de determinada forma e não de outra e quais são as estruturas, as disposições, que influenciam os sujeitos/atores em suas ações sobre o mundo, sobre a constituição dos campos sociais e como estes também orientam suas práticas. 
subsídios para pensar em práticas tanto clínicas quanto educacionais a partir da procura por esse serviço por universitários com dificuldades. A partir do exposto, será descrito algumas reflexões acerca do caso aqui pesquisado.

A participante desta pesquisa, Alice, aos 27 anos, decidiu ingressar no curso de Odontologia em uma Universidade federal do sul do Brasil. Acerca de sua história, resumidamente, a estudante comenta que residia no interior do estado localizado na região sul do país e teve que se mudar para a capital para poder estudar.

Sobre a família, Alice menciona que a mãe cursou até a $4^{\text {a }}$ série (atual $5^{\circ}$ ano do Ensino Fundamental), concluindo posteriormente os estudos através do Ensino de Jovens e Adultos (EJA). A mãe a acompanhou durante todo o trajeto, sendo que elas não têm contato com o pai. Alice também tem dois irmãos mais novos, que decidiram também seguir os estudos.

A minha mãe sempre me incentivou [a estudar]. As outras pessoas da minha família... é aquela coisa... não precisa estudar. Por que na minha família, das pessoas próximas, assim meus primos de primeiro grau, eu sou a primeira a entrar na faculdade, os outros não quiseram saber de estudar. Mas o pessoal estava mais preocupado em trabalhar. [...] [Acerca do curso de EJA]eu lembro que eu ia na escola com ela [mãe] por que ela não tinha com quem me deixar. Dai eu ficava lá na outra salinha, enquanto ela estava tendo aula. Aí às vezes minha mãe tirava foto e mandava para o grupo [da família no WhatsApp]. Ai agora ela saiu do grupo por que eles [a família] acham que ela quer se aparecer, que não tem necessidade de estudar. A minha mãe que sempre se esforçou para que eu estudasse por que ela era empregada doméstica quando era criança e ela também trabalhou em madeireira. Então ela não queria que eu tivesse essa vida e foi por isso que a gente saiu de lá [da cidade do interior]. Daí eu fiz meu Ensino Médio em Curitiba e depois vim para cá.

Alice revela que gosta de ler e não possui dificuldades, mas estas práticas são voltadas para a diversão/lazer e para aprender acerca da religião. Ela afirma que lê materiais principalmente impressos, sendo os gêneros religiosos e educacionais os mais lidos durante toda a sua vida. Além disso, outras práticas foram descritas: leitura de panfletos, placas, revistas infantis e ficção científica, poesia, anotações pessoais. Porém, quando as práticas de leitura se voltam para materiais da área acadêmica, as dificuldades aparecem. A estudante revela que lê muitas vezes o mesmo excerto de texto, que utiliza estratégias de estudo como uso de marca-texto, resumos, fichamentos, mas que, mesmo assim, durante as avaliações do curso, acaba trocando as informações ou percebendo que não compreendeu direito o conteúdo. 
Durante sua infância, a universitária comenta que havia práticas de mediação realizadas pela mãe, ao ler os livros emprestados da escola para ela. A estudante também comenta que fazia perguntas sobre o significado de palavras e outras questões, mas que, após ser alfabetizada, passou a estudar sozinha, sem procurar auxílio de outras pessoas. Quanto às práticas de escrita, Alice revela não gostar de escrever e suas práticas são restritas a trabalhos acadêmicos, lembretes pessoais e para enviar alguma mensagem a alguém. Durante a escolarização, a mãe e o padrasto a auxiliavam na escrita e nos cálculos matemáticos e ela também escrevia mais gêneros diversos devido às obrigações acadêmicas.

Após o ingresso na Universidade, contudo, suas práticas se reduziram a atividades acadêmicas e estudos religiosos. Mas as dificuldades que ela aponta, dizem respeito à dificuldade em iniciar a escrita e organizar e finalizar as ideias no texto. Além disso, ouviu comentários negativos sobre sua escrita, sua letra durante toda a vida, assim como ninguém a incentiva a escrever.

Acerca das práticas de numeramento, Alice comenta que nunca teve dificuldades, uma vez que seu ensino escolar não "demandava tanto". Sua procura se revela a partir do fato de que ela troca a lateralidade de números e isso está se tornando muito problemático em seu curso: ela precisa prescrever medicamentos e analisar o número de dentes e, por causa disso, vêm sofrendo represálias de colegas de curso e docentes. Portanto, surgiu a procura pelo diagnóstico de "discalculia", um diagnóstico que, possivelmente, a diferenciaria e poderia a auxiliar nas avaliações acadêmicas, retirando o "fardo" de "fracasso" que a rotula até então. O próprio encaminhamento reforçado por outros profissionais da saúde inculca nela essa ideia de que suas dificuldades não podem ser "normais", devem ser um "problema”. Acerca de suas dificuldades, ela relata que:

Eu sempre tive dificuldade, eu acho. Eu só percebi na faculdade, por que na escola era mais fácil. Por que na escola a cobrança era menor. Na escola tinham muito mais trabalhos, as provas eram mais fáceis... Tinham matérias que eu não estudava. Matemática que eu tive problemas assim desde a $8^{a}$ série... Eu nunca entendi direito [matemática], para falar bem a verdade. No Ensino Médio eu quase não tinha professor, por que era uma escola pública. [Na $2^{a}$ série do EM] a professora [de matemática] chamou minha mãe na escola e a professora estava me defendendo para a minha mãe: 'Não, mas ela é uma boa aluna, ela só tem essa dificuldade. Não briga com ela, ela senta aqui na frente, ela não fala'. Dai eu tive que fazer reforço um tempo. [...] Quando eu voltei para o cursinho, no primeiro dia de aula o professor deu um cálculo e perguntou: 'que que tem que fazer aqui?' $e$ geral? 'mmc!'. E eu não lembrava o que era mmc! Sabe, o significado da palavra mmc, que era mínimo múltiplo comum. E em casa assim o pessoal não era muito bom em matemática, nem minha mãe não era boa em matemática e meu padrasto sabia cálculo simples por que ele trabalhava em 
uma rodoviária vendendo passagem. Então não tinha que fazer altos cálculos assim. Eu não tinha muita ajuda em casa. [...] Português eu era melhor, mas agora que mudou as regras eu não sei mais escrever.

De acordo com Bourdieu (2012), após o ingresso na Educação Superior, há uma seleção que é desigual e os "fracassos" estariam mais concentrados nos estudantes que não herdaram o capital cultural exigido pelas instituições educacionais. Assim, se na escola traçam uma trajetória mediana ou acima da média - como no caso aqui descrito, é na Universidade que as desigualdades sociais e a heterogeneidade de transmissão cultural marcam a distinção entre os acadêmicos. Assim, há a seleção de uma cultura que é considerada legítima e digna de ser transmitida, reproduzida pela educação, transformando-se em uma moeda de troca que é detida e distribuída desigualmente entre as classificações sociais (LAHIRE, 2008) e servem para a manutenção de privilégios da ordem social. Portanto, as instituições educacionais (escola, Universidade), passariam a incluir estudantes e mantê-los em seu interior, mesmo que já destinando-os ao insucesso. Ou seja, por não fazerem parte daquela cultura exigida, os estudantes com dificuldades seriam de certo modo excluídos/marginalizados.

Nesse sentido, compreende-se que as práticas de leitura, escrita e numeramento a que a estudante esteve exposta não foram suficientes para prepara-la para as exigências acadêmicas. As mediações reveladas pela participante, principalmente com relação à escrita e numeramento, revelam-se sucintas e escassas. Esses dados podem ser observados também em outro estudo de Donida (2018), que aponta que as práticas de escrita em Universitários que procuram a clínica fonoaudiológica são incipientes e desconsideradas na academia, uma vez que a escrita de gêneros específicos dos cursos de graduação são mais priorizados devido ao novo lugar social que o estudante ocupa. Dessa forma, embora os universitários tenham práticas de Letramentos diversos, estes não são suficientes para que as dificuldades relacionadas às diferenças de aporte de capital cultural e simbólico, sejam percebidos e tornem-se fatores de distinção, o que, neste caso, foi traduzido como uma possível "alteração patológica".

É percebido também que tanto na Universidade como na escola, seriam instituídos certos domínios simbólicos de língua(gem) que induziria o professor a avaliar, consciente ou inconscientemente, o estudante de acordo com seu repertório linguístico, seu habitus ${ }^{6}$, sua

${ }^{6}$ O conceito de habitus é definido por Bourdieu (2001, p. 164) como: "Estrutura estruturante que organiza as práticas e a percepção das práticas, o habitus é também estrutura estruturada: o princípio de divisão em classes logicas que organiza a percepção do mundo social e, por sua vez, a produto da incorporação da divisão em classes sociais". O autor também menciona que o habitus, como "[n]ecessidade incorporada, convertida em RIAEE - Revista Ibero-Americana de Estudos em Educação, Araraquara, v. 16, n. 1, p. 341-360, jan./mar. 2021. e-ISSN: 1982-5587 
postura em sala de aula, sua capacidade de responder ao jogo escolar/universitário. Isso demonstra que há uma visão de "bom leitor", "bom escritor" e "bom aluno" como aquele que domina todas as práticas de leitura e escrita impostas pela academia e detém todos os conhecimentos necessários para aquele determinado campo (BOURDIEU; PASSERON, 2014[1964]; BOURDIEU, 2012) ${ }^{7}$.

Assim, as desigualdades sociais não deixam de marcar as trajetórias acadêmicas desses estudantes, observadas a partir da diferença de capital cultural (BOURDIEU, 2012; BOURDIEU; PASSERON 2014[1964]). A linguagem como um capital cultural, é reafirmada por Bourdieu (2012) que reitera que aqueles advindos de classificações populares acabam fracassando nas instituições de ensino, uma vez que não dominam as práticas exigidas nesse contexto, que requerem uma bagagem cultural diferenciada e um repertório linguístico que não condiz com a realidade daqueles menos desfavorecidos. Isso refletiria na qualidade da trajetória do estudante, que passa a ter dificuldades também com a linguagem utilizada pelo professor (BOURDIEU; PASSERON, 2014[1964]). A linguagem nesse contexto é vista como instrumento de dominação cultural e violência simbólica das classes dominantes para com as classes dominadas. No caso de Alice, essa distinção a coloca em uma situação delicada perante os professores e colegas:

Até o momento era Patologia, mas agora entramos em um assunto que eu
entendo melhor. É que é aquela história... Eu acho que entendi, mas aí na
hora que eu vou estudar parece que não está certo. [...] E quando tem que
decorar muito. Por exemplo, a gente teve uma matéria de terapêutica...
Terapêutica eu passei na tampa! Por que terapêutica tinha umas coisas que
era de cálculo de anestésico e eu tinha assistido uma palestra que eu tinha
entendido o cálculo, só que o professor explicou de uma forma diferente e
ele me confundiu muito e daí eu não sei fazer o cálculo que ele falou, eu sei
o cálculo da palestra, que era simples... E a prova dele era de você lembrar
o nome do medicamento... era decoreba mesmo... Tinha o nome do
medicamento e dosagem e era muito medicamento... E eu não lembrei... E
ele colocou uns remédios que dentista geralmente não usa, aí eu fiquei 'não
sei'. Ou então eu acertava o medicamento e errava a dosagem. [...] É mais
dificil pedir ajuda para o professor. Às vezes eu peço ajuda para o monitor

disposição geradora de práticas sensatas e de percepções capazes de fornecer sentido as práticas engendradas dessa forma, o habitus, enquanto disposição geral e transponível, realiza uma aplicação sistemática e universal, estendida para além dos limites do que foi diretamente adquirido, da necessidade inerente as condições de aprendizagem $[\ldots . .$. ".

7 "“...] o habitus linguístico diz respeito ao conjunto de disposições adquiridas ao longo de um processo no qual se aprende a falar em contextos específicos (com a família, com os amigos, com os superiores e os subalternos, etc.). Essas disposições levam o agente social a falar de uma determinada maneira (mantendo uma relação específica com a língua dita padrão e exibindo um certo sotaque, por exemplo). Além disso, tais disposições constituem-se numa das dimensões da hexis corporal, e dizem respeito também à forma como são utilizadas a boca, o lábio, o tom de voz, entre outros, nas interações linguísticas, o que implica um estilo, assim como a apreciação que se faz desse estilo (bonito, feio, elegante, deselegante, feminino, masculino, etc.)" (ALMEIDA, 2002, p. 19). 
ou para algum colega que entendeu melhor que eu. [...] Tem professor que parece que intimida você. Assim, se fizer pergunta ele já te olha com uma cara de 'você é burro? Você não sabe disso?'. Aconteceu isso com alguns professores... inclusive aconteceu com um daqui e deu muita raiva... por que eu perguntei assim pra ela e ela falou: 'Mas você vai pegar paciente e não vai saber?'. A vontade que eu tive foi de olhar para a cara dela e falar: 'Mas eu não estou na frente de um paciente, professora. Estou perguntando para você!'. [...] A relação com meus colegas... não tem, na real. $\mathrm{Na}$ verdade eu tenho uma amiga, que é a que reprovou comigo... [...] Ai geralmente nos outros cursos eu não converso com ninguém. A odonto por si só, quando você reprova, você acaba ficando amigo de quem reprovou, por que as pessoas das turmas são muito fechadas, elas já têm os grupos [...] e dificilmente você consegue se inserir em um grupinho já fechado.

Os campos sociais são abstrações espaciais que definem posições e relações em que agentes/sujeitos específicos atuam. Dito isso, compreende-se que existem vários campos na sociedade e eles podem assumir posições hierárquicas nas classificações sociais, de maior ou menor poder, sendo historicamente construídos e situados (BOURDIEU, 2012). O curso de Odontologia, por exemplo, ocupa um lugar historicamente construído e demarcado por uma perspectiva clínico-biológica. Logo, a inserção da estudante nesse contexto requer uma aculturação. Ou seja, Alice precisa mobilizar estratégias para contornar suas dificuldades e de adaptar às exigências do curso. Ocorre que, essas estratégias são recursos aprendidos a partir da mobilização de certo tipo de capital cultural e simbólico que não lhe foram transmitidos $o$ jogo de estratégias para se inserir neste campo social não foi a herança cultural que ela detém (BOURDIEU, 2012). No tocante aos usos de leitura e escrita, Bourdieu (2011[1984]) ressalta que cada campo universitário determina os valores das práticas de leitura e escrita, os usos estilísticos mais ou menos literários, mais ou menos neutros e dotados de rigor técnico e que também circunscrevem a posição do sujeito no interior desse campo.

O fato é que, os incluídos permanecem por mais tempo nesse sistema, sem, contudo, poderem ascender socialmente. Eles são os chamados excluídos em potencial, ou seja, estão incluídos em um sistema educacional que tende à excluí-los ao passo em que as exigências, os habitus, das instituições de educação aproximam-se daquele das elites (BOURDIEU, 2001). Assim, o afastamento de práticas de Letramento adotadas pela Universidade daquelas vivenciadas no contexto familiar e escolar e os modos de reprodução que perpetuam acepções sobre o modus operandi das instituições de ensino, afastam cada vez mais os estudantes que se sentem despreparados para essa nova situação de interação e de uso da linguagem (BOURDIEU; PASSERON, 2014[1964]). É nesse contexto que o sistema educacional brasileiro também se encontra como reprodutor de desigualdades sociais, mesmo quando, no seio da Educação Superior, se discute acerca da inclusão dos "excluídos". 
Para atender as demandas frente às dificuldades de permanência na instituição e diminuir a repetência e a evasão, o Programa Nacional de Assistência Estudantil (PNAES) orienta que as Universidades ofereçam apoios pedagógicos (BRASIL, 2010). Essa "solução" é proposta de modo a diminuir as dificuldades acadêmicas que têm como origem distintas transmissões de capital cultural desses novos estudantes que adentram na Educação Superior. Contudo, Alice revela que desconhece os trabalhos do apoio pedagógico na instituição em que frequenta. E mais: reconhece que em seu curso não há apoio "geral” que possa auxiliá-la, uma vez que há especificidades que são próprias deste campo do saber universitário e que não são contempladas em oficinas ou extensões gerais voltadas a toda a comunidade acadêmica. Reitera-se que há ações de monitorias em seu curso, contudo, acredita-se que quando a acadêmica se refere a "apoio geral", ela esteja denotando que as dificuldades ultrapassam um caráter puramente pedagógico, obstáculos estes que foram mencionados acima.

Apesar do desconhecimento, a conduta clínica após a avaliação fonoaudiológica foi encaminhar esta estudante para o apoio pedagógico da instituição, uma vez que suas dificuldades não se enquadravam no escopo de atendimento clínico, disponibilizando-se para ações conjuntas e parcerias com o apoio pedagógico e a coordenação do curso. É relevante ressaltar que a Fonoaudiologia possui uma especialidade que se incumbe da atuação no meio educacional: a Fonoaudiologia Educacional. Esse profissional pode atuar na Educação Superior, integrado às equipes institucionais, com o objetivo de propor e desenvolver estratégias e ações que visam melhorar a qualidade de permanência e de trajetória educacional dos estudantes, diminuindo a evasão e adequando os processos de ensino e aprendizagem (DONIDA; SANTANA, 2019). A instituição à qual a universitária está vinculada, contudo, não possui um fonoaudiólogo educacional que atue no Apoio Pedagógico, somente no Núcleo de Acessibilidade. Apesar disso, acredita-se que esse profissional poderia promover ações situadas que contemplassem as especificidades dos cursos e das dificuldades encontradas no bojo da presente Universidade (DONIDA; SANTANA, 2019).

Nesse sentido, compreende-se que para que a educação seja inclusiva, ou seja, contemple todas as diferenças e a diversidade encontrada no interior nas instituições educacionais é necessário que novas práticas de ensino e de aprendizagem sejam adotadas dentro da instituição. Nesse ínterim, concebe-se que o Desenho Universal para a Aprendizagem (DUA) emerge como um instrumento teórico-epistemológico que tem como objetivo favorecer as oportunidades de aprendizagem para todos, em um processo colaborativo de ensino e aprendizagem entre estudantes e educadores. Por meio de estratégias, práticas e o desenvolvimento de materiais, métodos e avaliações eficientes, oferece aos 
educadores uma proposta inclusiva que potencializa as capacidades e habilidades de cada educando. Dessa forma, minimiza "as barreiras no percurso acadêmico de estudantes com e sem deficiência, não hierarquizando ou privilegiando um único modo de aprender e, com isso, criando ambientes de aprendizagem flexíveis para estudantes e docentes" (BOCK; GUESSER; NUERNBERG, 2018, p. 145).

A partir do que propõem Rose e Meyer (2002) acerca dos princípios do DUA, de que cada estudante possui redes afetivas ("o porquê" aprender), redes de reconhecimento ("o que" aprender) e redes estratégicas (“como" aprender") próprias (CAST, 2018). Além da produção de todo o material e ferramentas pedagógicas, o foco da aprendizagem do DUA está no estudante e no seu processo de aprender, partindo-se assim, do desenvolvimento de suas habilidades tanto coletivamente como individualmente. Para isso, é preciso que o professor esteja atento as diferentes necessidades de aprendizagem de cada estudante, entendo-os a partir de uma heterogeneidade de saberes, de experiências e de como pode ampliar esses conhecimentos que os estudantes trazem para a escola. Deixar os objetivos de aprendizagem claros, ou seja, do ponto de onde se quer partir para onde se quer chegar, permite gerar uma expectativa no estudante que ele consiga alcançar esse objetivo a partir das diferentes estratégias utilizadas nesse processo (HOLLAND, 2014). Pode-se perceber que a participante da presente pesquisa poderia ter melhorias em seu desempenho acadêmico, a partir do que a própria menciona:

Ouvindo eu entendo melhor do que só lendo. Eu tenho que ler várias vezes a mesma coisa para entender. Eu tenho que fazer resumos para estudar ou tem algumas matérias que tem o roteiro. Aí o meu roteiro é todo rabiscado, por que aí com base no que tenho que estudar, eu acabo escrevendo por cima, fazendo flechas, passo marca-texto, coisas assim. Quando é texto que o professor passa, eu prefiro imprimir para ler do que no computador, por que ai eu posso riscar. Durante as aulas, quando tem professor que passa o material, eu acabo mais ouvindo do que escrevendo. Quando o professor não disponibiliza, eu acabo escrevendo mais, anotando o que ele falou, para depois eu poder procurar no livro algo parecido. Quando eu não faço isso, eu tenho mais dificuldade.

Com uma perspectiva de DUA, poderia ser oferecido aos estudantes melhorias nos processos de ensino e aprendizagem, diminuição da evasão nos cursos, aumento da qualidade na formação, diminuição de problemas emocionais entre os acadêmicos, entre outras. Contudo, como aponta Noronha (2019), os cursos da saúde ainda estão em fase embrionária quando o assunto se refere a mudanças nos currículos e nos processos de ensino e aprendizagem. Segundo a autora, o Letramento Digital - que são práticas de leitura, escrita e oralidade/sinalização utilizadas e promovidas a partir do advento das Tecnologias Digitais de 
Comunicação e Informação (TDICs) - ainda é pouco explorado. As pesquisas voltadas ao uso de letramentos digitais (podcasts, plataformas e-Learning, Youtube, Realidade Virtual e Aumentada, gamification, entre outros) também são poucas e incipientes, revelando até certo desconhecimento na área da saúde acerca dessa temática.

O fardo, contudo, reside no modo como essas mudanças poderiam ser implementadas na instituição. Para os docentes que recém ingressaram, há a possibilidade de formação através de cursos oferecidos pela Universidade. Mas, para muitos, ainda há desconhecimento e preconceito sobre as dificuldades presentes no ambiente de ensino: mecanismos de manutenção e de reprodução das desigualdades sociais. Segundo pesquisa de Santana et.al. (2017), há docentes na Educação Superior que acreditam que estudantes público-alvo da Educação Especial ou com Transtornos Funcionais Específicos não deveriam ter acesso aos cursos de graduação. $\mathrm{Ou}$, ainda, consideram que as dificuldades se restringem à "preguiça" por parte do acadêmico e que suas práticas, avaliações e metodologias de ensino e aprendizagem não devem ser modificadas para não ser "privilegiar" um ou outro aluno.

Para observar quais práticas são consideradas importantes em determinado contexto e como se constituem, deve-se considerar que há diferentes modos de transmissão cultural, que há desigualdades sociais e que as diferentes formas de acesso e apropriação da linguagem escrita podem gerar exclusão do sistema educativo (BOURDIEU, 2012). Assim, quando um universitário não domina práticas de leitura, escrita, oralidade e numeramento que lhe são esperadas, pode ser marginalizado e até excluído dentro da instituição. Até porque o próprio meio acadêmico se configura de acordo com sua especificidade e exige domínio de determinadas práticas em detrimento de outras. O desafio, portanto, é considerar esse perfil e pensar em estratégias de permanência, de reparação.

\section{Considerações finais}

Este trabalho teve como objetivo compreender como as desigualdades sociais originam dificuldades de leitura, escrita, aritmética e oralidade e como essas questões de ordem social são transformadas em supostos diagnósticos clínico-biológicos em estudantes da Educação Superior. Sabendo-se que as dificuldades são estruturais em nossa sociedade e as instituições de ensino reproduzem formas de manutenção das desigualdades, este estudo de caso se propõe a desvelar alguns mecanismos que perpassam a vida acadêmica e que não são percebidos (ainda) como formas de exclusão na Universidade. 
A partir disso, o caso da estudante Alice revela que suas dificuldades educacionais se revelaram como um empecilho aos seus estudos após o ingresso na Educação Superior. A queixa que justifica seu encaminhamento para uma avaliação fonoaudiológica clínica referese a um suposto diagnóstico de "discalculia". Contudo, após avaliação cuidadosa acerca de sua trajetória de vida, observou-se que suas dificuldades são, antes de tudo, reflexo da desigualdade social que nosso país ainda enfrenta: poucas práticas de ensino e aprendizagem significativas durante o período escolar; falta de professores; déficits de conteúdos escolares básicos; dificuldades socioeconômicas; distanciamento com o aculturamento das práticas de Letramentos exigidas na Universidade. É notório, também, que o capital cultural repassado pela família não foi suficiente para que Alice desenvolvesse estratégias para se inserir no campo de saber ao qual ingressou: a Odontologia. Com isso, também se revela manutenções de hierarquias de poder simbólico (e de certa forma, de violência simbólica) por parte de docentes e colegas.

Dessa forma, haveria a necessidade de mudanças nas estruturas estruturantes da instituição de ensino, as quais sustentam as reproduções de formas de exclusão. Essas mudanças poderiam ocorrer a partir da adoção do Desenho Universal para a Aprendizagem (DUA), em diversos sentidos: partindo do corpo docente do curso para mudanças curriculares, de ensino e de aprendizagem; da coordenação do curso para reestruturação curricular e formação dos docentes; da Universidade, a âmbito institucional, reestruturando currículos, capacitando os docentes e técnicos, formando novas propostas de ações que atenderiam às demandas específicas de cada curso, etc. Contudo, sabendo-se que a desigualdade social é um problema estrutural de nossa sociedade, há a necessidade de que novas pesquisas sejam empreendidas em profundidade para revelar quais são os mecanismos intrínsecos de cada curso que fazem com que a exclusão de estudantes seja algo ainda vigente.

Assim, compreender e problematizar essas questões na Educação Superior é a principal contribuição deste trabalho. Não se espera que esse trabalho dê conta de toda a complexidade desse universo acadêmico, heterogêneo em sua constituição, mas sim, que ele forneça subsídios para pesquisas que compreendam que as dificuldades de universitários e não as reduzir a questões meramente medicalizadoras/biológicas. 


\section{REFERÊNCIAS}

ALMEIDA, A. M. Notas sobre a sociologia do poder: a linguagem e o sistema de ensino. Horizontes, Bragança Paulista, v. 20, p. 15-30, jan./dez. 2002. Disponível em: http://www.titosena.faed.udesc.br/Arquivos/Textos_para_aulas/notas_sobre_a_sociologia_do _poder.pdf. Acesso em: 15 nov. 2019.

APA. AMERICAN PSYCHIATRY ASSOCIATION. Diagnostic and Statistical Manual of Mental disorders - DSM-5. 5. ed. Washington: American Psychiatric Association, 2014.

BOCK, G. L. K.; GESSER, M.; NUERNBERG, A. H. O desenho universal para aprendizagem no acolhimento das expectativas de participantes de cursos de educação a distância. Revista Educação Especial, Santa Maria, v. 32, jun. 2019. DOI: http://dx.doi.org/10.5902/1984686X34504

BOURdieU, P. (Org). A Miséria do Mundo. Petrópolis/RJ: Vozes, 2001.

BOURDIEU, P. Homo academicus. Trad. Ione Ribeiro Valle; Nilton Valle, Rev. Téc. Maria Tereza de Queiroz Piacentini. Florianópolis: Ed. da UFSC, 2011[1984].

BOURDIEU, P. Escritos de educação. 14. ed. Petrópolis: Editora Vozes, 2012.

BOURDIEU, P.; PASSERON, J. Os herdeiros: os estudantes e a cultura. Florianópolis: Ed. da UFSC, 2014[1964].

BRASIL. Decreto n. 6.096, de 24 de abril de 2007. Institui O Programa de Apoio A Planos de Reestruturação e Expansão das Universidades Federais. Brasília, Disponível em: http://www.planalto.gov.br/ccivil_03/_ato2007-2010/2007/decreto/d6096.htm. Acesso em: 25 nov. 2019.

BRASIL. Decreto n. 7.234, de 19 de julho de 2010. Dispõe Sobre O Programa Nacional de Assistência Estudantil. Brasília. Disponível em:

http://www.planalto.gov.br/ccivil_03/_Ato2007-2010/2010/Decreto/D7234.htm. Acesso em: 17 nov. 2019.

BRASIL. Lei n. 12.711, de 29 de agosto de 2012. Dispõe Sobre O Ingresso nas

Universidades Federais e nas Instituições Federais de Ensino Técnico de Nível Médio e Dá Outras Providências. Brasília, 2012. Disponível em:

http://www.planalto.gov.br/ccivil_03/_ato2011-2014/2012/lei/112711.htm. Acesso em: 27 nov. 2019.

IBGE. INSTITUTO BRASILEIRO DE GEOGRAFIA E ESTATÍSTICA. Síntese de Indicadores 2012. 2012. Disponível em:

http://www.ibge.gov.br/home/estatistica/populacao/trabalhoerendimento/pnad2012/default_si ntese.shtm. Acesso em: 1 nov. 2019.

CAST. Universal design for learning. Guidelines version 2.2, 2018. Disponível em: http://udlguidelines.cast.org. Acesso em: 18 dez. 2019. 
CAVACO, C. J. D. Adultos pouco escolarizados diversidade e interdependência de lógicas de formação. 2008. Tese (Doutorado) - Faculdade de Psicologia e de Ciências da Educação, Universidade de Lisboa, Lisboa, 2008. Disponível em:

https://repositorio.ul.pt/bitstream/10451/972/1/17505_ulsd_re286_TD_Carmen_Cavaco3.pdf. Acesso em: 12 dez. 2019.

D’AMBROSIO, U. Etnomatemática, justiça social e sustentabilidade. Estudos Avançados, São Paulo, v. 32, n. 94, p. 189-204, 2018. DOI: https://doi.org/10.1590/s010340142018.3294 .0014

DONIDA, L. O. Universitários com dificuldade de leitura e escrita: desvelando discursos. 2018. 145 f. Dissertação (Mestrado em Linguística) - Universidade Federal de Santa Catarina, Florianópolis, 2018. Disponível em:

https://repositorio.ufsc.br/bitstream/handle/123456789/194394/PLLG0731-D.pdf?sequence=1\&amp;isAllowed=y. Acesso em: 2 mar. 2020.

DONIDA, L. O.; SANTANA, A. P. Apoio Pedagógico como proposta de educação para todos. Educ. Pesqui., São Paulo, v. 45, e192527, 2019. DOI: https://doi.org/10.1590/s16784634201945192527

DONIDA, L. O.; POTGURSKI, D. S.; POTTMEIER, S.; ELIASSEN, E. S.; SANTANA, A. P. O. Letramentos Digitais: Mediadores Do Processo De Inclusão Educacional? In:

COLÓQUIO INTERNACIONAL DE EDUCAÇÃO ESPECIAL E INCLUSÃO ESCOLAR, 2019, Florianópolis. Anais [...]. Campinas: Galoá, 2019. Disponível em:

https://proceedings.science/cintedes-2019/papers/letramentos-digitais--mediadores-noprocesso-de-inclusao-educacional--?lang=pt-br. Acesso em 18 nov. 2019.

ELIASSEN, E. S. A discursivização do diagnóstico da dislexia: da teoria à prática. 2018. 224 f. Dissertação (Mestrado em Linguística) - Universidade Federal de Santa Catarina, Florianópolis, 2018. Disponível em: https://repositorio.ufsc.br/handle/123456789/205753. Acesso em 19 dez. 2019.

HOLLAND, B. Desenho universal para aprendizagem: um guia para o sucesso escolar. Diversa, 2014. Disponível em: https://diversa.org.br/artigos/desenho-universal-paraaprendizagem-guia-sucesso-escolar/. Acesso em: 27 mar. 2019.

IBLC. Instituto Brasileiro de Letramento Científico (Org.). ILC - Indicador de Letramento Científico: Sumário executivo de resultados. 2018. Disponível em: http://iblc.org.br/wpcontent/uploads/2018/01/1-relatorio-executivo-ilc-fcc.pdf. Acesso em: 23 mar. 2020.

INSTITUTO PAULO MONTENEGRO, AÇÃO EDUCATIVA. Inaf Brasil 2018: resultados preliminares. Disponível em: http://acaoeducativa.org.br/wpcontent/uploads/2018/08/Inaf2018 Relat\%C3\%B3rioResultadosPreliminares_v08Ago2018.pdf. Acesso em: 8 set. 2018.

LAHIRE, B. Sucesso escolar nos meios populares: As razões do improvável. São Paulo: Ática, 2008.

NOGUEIRA, M. A.; NOGUEIRA, C. M. M. Bourdieu \& a Educação. 2. ed. Belo Horizonte: Atlântica, 2014. 
NORONHA, M. G. O uso de TDICs na prática fonoaudiológica para a linguagem escrita: revisão da produção acadêmica nas revistas brasileiras de fonoaudiologia. 2019. Monografia (Trabalho de Conclusão do Curso de Fonoaudiologia) - Centro de Ciências da Saúde (CCS), Universidade Federal de Santa Catarina, Florianópolis, 2019.

OLIVEIRA, A. M.; ACOSTA, R. P. Os gêneros do discurso na esfera acadêmica: reverberações dialógicas. Letras, Santa Maria-RS, n. 58, p. 13-36, set. 2019. ISSN 21761485. DOI: https://doi.org/10.5902/2176148534195

RODRIGUES, A. Movimentos escolarizados e não escolarizados: do corpo aluno e suas estratégias de resistência. Revista Contemporânea de Educação, v. 9, n. 18, 2014. DOI: https://doi.org/10.20500/rce.v9i18.1858

ROSE, D. H.; MEYER, A. Teaching every student in the digital age: universal design for learnig. Alexandria, VA: ASCD, 2002. Disponível em:

http://www.ascd.org/publications/books/101042.aspx. Acesso em: 16 abr. 2019.

SANTANA, A. P.; DARDE, A. O. G.; SANTOS, K. P.; DONIDA, L. O.; POTTMEIER, S. Educação Superior e recursos de acessibilidade na visão de professores e estudantes. In: LEITE, L. P.; MARTINS, S. E. S. O.; VIELLELA, L. M. (Org.). Recursos de acessibilidade aplicados ao ensino superior. 2. ed. São Paulo, SP: Cultura Acadêmica, 2017. v. 1. p. 133156.

SANTANA, A. P.; SANTOS, K. P. A perspectiva enunciativo-discursiva de Bakhtin e a análise da linguagem na clínica fonoaudiológica. Bakhtiniana, Rev. Estud. Discurso, São Paulo, v. 12, n. 2, p. 174-190, ago. 2017. DOI: http://dx.doi.org/10.1590/2176-457327491

SENHORINI, G.; SANTANA, A. P. O.; SANTOS, K. P.; MASSI, G. A. O processo terapêutico nas afasias: implicações da neurolinguística enunciativo - discursiva. Rev. CEFAC, São Paulo, v. 18, n. 1, p. 309-322, 2016. DOI: http://dx.doi.org/10.1590/19820216201618117214

STREET, B. Letramentos sociais: abordagens críticas do letramento no desenvolvimento, na etnografia e na educação. Trad. Marcos Bagno. São Paulo: Parábola, 2014.

UNESCO. United Nations Educational Scientific And Cultural Organization (Ed.).

Education for people and planet: creating sustainable futures for all. 2. ed. Paris: Unesco, 2016. 535 p. (Global edu). Disponível em:

http://unesdoc.unesco.org/images/0024/002457/245752e.pdf. Acesso em: 1 nov. 2019. 


\section{Como referenciar este artigo}

DONIDA, L.; BLANCO, S. F. M. M. Dificuldades de leitura, escrita e numeramento na educação superior: discussões acerca da reprodução das desigualdades sociais. Revista IberoAmericana de Estudos em Educação, Araraquara, v. 16, n. 1, p. 341-360, jan./mar. 2021. eISSN: 1982-5587. DOI: https://doi.org/10.21723/riaee.v16i1.13551

Submetido em: 09/04/2020

Aprovado em: 19/08/2020

Publicado em: 02/01/2021 